\title{
Sports Dentistry: A Narrative Review
}

\section{HENNA MIR*1 (D), SHIVALINGESH KK² (D), CHANCHAL GANGWAR³, WASEEM ASHRAF4 (D)}

Sports dentistry originated in 1980s. Most of the sports-related injuries are musculoskeletal. There are various factors which are responsible for the sports injury like the age, gender, growth, body size, type of sports, environmental conditions etc. and sports dentistry includes the prevention and management of it. There are various methods for avoiding oral sports injuries like the use of helmets, mouthguards, facemasks etc. The dentist can play an important role in informing coaches and sportspersons about the importance of preventing orofacial injuries. The aim of this review article is to increase professional awareness towards sports dentistry.

KEYWORDS: Injuries, Dentistry, Awareness, Sports

\section{INTRODUCTION}

Sports dentistry is the dental branch that was founded in 1958, Brazil at the time of World Cup Soccer. As per International Academy for Sports Dentistry - "Sports Dentistry is referred to as the sports medicine division that deals with the prevention and treatment of dental injury and related oral diseases associated with sports and exercise". It has two major components: The first is the treatment of orofacial injuries and the second is the prevention of orofacial injuries due to sports. ${ }^{2}$

A specialization is required to meet all these criteria and it seems that sports dentistry is the need of time. Current dentistry has fortunately evolved various methods and devices to help and protect the participants from a number of orofacial injuries. ${ }^{3}$ Preventive measures such as the use of helmets, mouthguards, and other safety devices have reduced the athlete's impact, thereby reducing the injury. ${ }^{2}$ Studies showed that $13 \%-39 \%$ of all dental incidents were sports-related and $11 \%-18 \%$ of all sports related deaths were from maxillofacial injuries. ${ }^{4}$ Sport-related oral damage is seen primarily in school children aged 7 to 11 years. Dental injuries most commonly encountered during sports are as follows:
1. Soft-tissue lacerations
2. Contusions
3. Dental fractures
4. Root fractures
5. Avulsions

\section{Dentoalveolar fractures}

7. Mandibular dislocations. ${ }^{5}$

Most of the sports-related injuries are musculoskeletal, and the face is involved in $11-40 \%$ of all sports injuries. Males are twice as often traumatized as females, the maxillary central incisor being the most often injured tooth. Age group of 20 and 30 year old individuals are most often affected by jaw fractures, because the maxilla is the facial skeleton's largest component. The most severe forms of facial trauma associated with athletics are soft tissue injury and "Tzone" bone fractures; the nose, zygoma, and mandible.1 As a result of the potential for pain, psychological impact and economic implications, the impacts of orofacial abuse for children and their families are significant. ${ }^{6}$ Therefore the aim of this review was to assemble the knowledge regarding the epidemiology and prevention of sports related injuries.

\section{SPORTS INJURIES}

The face is the body's most vulnerable area, and is normally the least protected. Facial injuries associated with sports account for $8 \%$ of all soft tissue injuries to the face. Around $11-40 \%$ of all sports injuries include the face. Most injuries can be treated at the sporting event venue, depending on the extent and the forms of damage, with the athlete resuming to play immediately. Particularly vulnerable are three groups:

(C) Henna Mir et al. This is an open access article distributed under the terms of the Creative Commons Attribution License CC-BY-NC 4.o, which permits unrestricted use, distribution and reproduction in any medium, provided the use is not commercial and the original author(s) and source are cited. 
children and teenagers, middle-aged athletes and women. Contact sports have inherent risks that place young people at a high risk of serious injuries. Biking is the top most sport related injury which is followed by basketball, playground activities, football and a few other sports. Some sport injuries are caused by accidents; others are caused by poor fitness methods, inadequate gear and lack of preparation or insufficient warm-up and stretch. ${ }^{7}$

\section{PREVALENCE OF OROFACIAL INJURIES}

The prevalence of orofacial injuries during carious contact sports are shown in table $1 .{ }^{8}$

\begin{tabular}{|c|c|c|c|}
\hline $\begin{array}{c}\text { CONTACT } \\
\text { SPORT } \\
\end{array}$ & PREVALENCE & AUTHOR & YEAR \\
\hline $\begin{array}{l}\text { 1. Basket } \\
\text { Ball }\end{array}$ & $\begin{array}{c}80.6 \% \\
\text { (Professionals) } \\
37.7 \% \\
\text { (semiprofessionals) }\end{array}$ & $\begin{array}{c}\text { Wenli Ma et } \\
\text { al. }\end{array}$ & 2008 \\
\hline $\begin{array}{c}\text { 2. Base } \\
\text { Ball }\end{array}$ & $27 \%$ & $\begin{array}{c}\text { Pasternack } \\
\text { JS et al. }\end{array}$ & 1996 \\
\hline $\begin{array}{c}\text { 3. Foot } \\
\text { Ball }\end{array}$ & $16.6 \%$ & $\begin{array}{c}\text { Esber C, } \\
\text { Aglar et al. }\end{array}$ & 2009 \\
\hline $\begin{array}{c}4 \\
\text { Handball } \\
\end{array}$ & $21.8 \%$ & Galic T et al. & 2018 \\
\hline $\begin{array}{c}\text { 5. Water } \\
\text { polo } \\
\end{array}$ & $18.6 \%$ & Galic T et al. & 2018 \\
\hline $\begin{array}{l}\text { 6. Swiss } \\
\text { Rugby }\end{array}$ & $39 \cdot 5 \%$ & $\begin{array}{l}\text { Schildknecht } \\
\text { S et al. }\end{array}$ & 2012 \\
\hline 7. Hockey & $33.8 \%$ & $\begin{array}{c}\text { Praveena J et } \\
\text { al. }\end{array}$ & $2018^{8}$ \\
\hline
\end{tabular}

Table 1. Prevalence of Orofacial Injuries while Playing Contact Sports

\section{EVALUATION OF FACIAL INJURIES}

Assessment of facial injuries should follow the principles of trauma assessment and should continue with airways, breathing circulation and disability. Vital sign examination and mental stability are also critical components of initial evaluation. The first and main aspect of assessing trauma patients is called the primary survey. The problems will be dealt with in an ABCDE manner (A- airway, B- breathing, Ccirculation, D- disabilities and E - exposed environment control). The secondary survey will begin when the primary survey is complete, resuscitation attempts are well defined, and the vital signs are normalizing. The secondary assessment is a trauma patient's head-to-toe assessment, including a complete history and physical examination, and reassessing all vital signs. Every area of the body needs to be investigated in full. X-rays are obtained, suggested by examination. If the patient deteriorates at any point during the secondary study, another primary survey will be carried out, as there may be a potential life threat. The patient should be removed from the hard spine board and put on a firm mattress as soon as realistically possible as the spine board can easily cause skin deterioration and discomfort whilst a firm mattress offers equal protection for suspected spinal fractures. All soft tissue trauma and apparent facial contour asymmetries (suggesting structural bony fractures) are recorded once the potentially lifethreatening injuries are removed. This is accompanied by a thorough face examination. To provide for a thorough examination, each health care provider must establish a standardized procedure. A common approach starts with the scalp and works downwards.7

The face is implicated in about $11-40 \%$ of all sports injuries. The intricate facial anatomy poses a challenge for the doctors to diagnose and treat these injuries. 9 In Austria, Tuli et al. stated that sport accidents are six times more likely to cause facial injuries than accidents at work or accidents at traffic, respectively.

\section{EPIDEMIOLOGY OF OROFACIAL INJURIES}

The host - agent - environment can be adapted for understanding the epidemiology of sports injuries.

1. Host Factors: Host factors can be determined by the following:

i). Age: Degenerative changes in the bone, ligaments, and other connective tissues in older players may be an important etiological factor for injury. Primary dentition most often contributes to luxation injuries before the eruption of th permanent incisors. A smaller association of crown to root with denser and more mineralized alveolar bone is apparently leading to this phenomenon. ${ }^{10}$

ii). Gender: The evidence supports the fact that boys seem more vulnerable than girls to orofacial injury. This fact is consistent with the National Youth Safety Sports Foundation (NYSSF) 1994 ratio 3:1, which breaks down to 2:2 injuries per 100 girls per season and 3.9 injuries per 100 boys per season for overall injury 
risk in organized sports. ${ }^{11}$ Nonetheless, Pinkham and Kohn say that when taking into account the exposure levels, girls are at higher risk than boys. ${ }^{12}$

iii). Growth: The developing child needs to quickly adjust the learned skills to the changing dimensions of his or her body. A theory suggests that children are at great injury risk at accelerated points in their growth rates as the growth is reflected first in the long bones of the body, then in the muscles. The most frequent cause of overall injury in adolescents may be the loss in flexibility."

iv). Body size: These include a higher center of gravity, increased leverage due to greater length of limbs and stress on joints due to additional weight. ${ }^{12}$

v). Skilled coaching: An athlete is less able to respond in game situations without proper instruction and guidance or coaching in physical fitness and sporting skills, thereby increasing the risk of injury.

vi). Orthodontic status and history of previous injury: The factors like class II molar relationship having an overjet greater than $4 \mathrm{~mm}$., short upper lip or incompetent lips, and mouth breathing all increase risk for dental injury.

2. Psychological factor: The state of mind during play has a lot to do with the concentration level and the ability to perform in the sports. There is a more risk for injury if the athlete is having more stress or pressure levels. ${ }^{10}$

\section{Agent factors:}

i) Type of sport: It would seem that fast moving sports are predisposed to injury as a result of collisions. Sports that use projectiles such as balls, pucks or some form of a stick are also associated with increased risk involvement. Soft tissue lacerations and contusions as well as displaced comminuted - type fractures are frequently associated with the sports having the use of bats, hockey sticks and other sports having same armamentaria.

ii). Other factors: The playing field conditions and the fit of the safety equipment affect the amount of danger the athlete is exposed to. Lack of regulations or officials ' ability to implement them often increases the risk. ${ }^{11}$

\section{Environmental factors:}

i) Occasionally, in some of the unforcing situations, environment factors such as light condition (e.g. dull light), disrupted air conditions, humidity conditions, and rain can also cause the sports person to encounter impaired physical and psychological conditions, which can lead to direct or indirect injury.

ii) As explored through discrepancies in urinary catecholamines, children with emotionally stressful conditions face a greater risk of injury to the dentofacial region. ${ }^{11}$

\section{PREVENTION OF OROFACIAL INJURIES}

The main method for avoiding oral sports injuries is to wear mouth guards and headgear consisting of a mask and face protector (Table 2).

1. Mouth guards: The first mouthguard documented was made in 1892 by London Dentist, Woolf Krause. ${ }^{13}$

\begin{tabular}{|c|c|c|}
\hline \multicolumn{3}{|c|}{ SPORTS THAT REQUIRE THE USE OF } \\
MOUTHGUARDS \\
\hline Acrobatics & Handball & Soccer \\
\hline Basketball & Ice hockey & Softball \\
\hline Bicycling & Gymnastics & Squash \\
\hline Boxing & Martial arts & Surfing \\
\hline Extreme sports & Rugby & Volleyball \\
\hline
\end{tabular}

Table 2. Sports Requiring the Use of Mouthguards

The American Society for Testing and Materials and mouthguard manufacturers divided the mouthguard into three types:

i). Stock Mouthguards: Stock mouthguards are made from rubber, polyvinyl chloride, or a copolymer of polyvinyl acetate. The advantage is that it is relatively inexpensive and the disadvantage is its availablity only in limited sizes. ${ }^{14}$

ii) Mouth-formed Protectors: There are two types of mouth-formed protectors: The shell-liner and the thermoplastic mouthguard. The shell-liner type is manufactured by inserting freshly mixed ethyl methacrylate in a hard shell, which is then placed into the athlete's mouth and molded over the maxillary 
teeth and soft tissue. ${ }^{15}$ The preformed or thermoplastic (also known as "boil and bite") is immersed in boiling water for 40-45 seconds transferred to cold water and then adapted to the teeth. ${ }^{6}$

iii) Custom Made Mouth Protectors: This is the best of the three forms and the most expensive, it is made of thermoplastic polymer and constructed over a dentition model of the sportsperson and designed by the dentist and matches exactly the fit of the mouth of the sportperson. ${ }^{16}$

2. Helmet: Helmets are designed to avoid abrasions, contusions and lacerations in the scalp and ears. These protect the skull bones against fractures, and the brain and central nervous system against severe concussions, cerebral hemorrhage, unconsciousness, paralysis, brain damage and death. ${ }^{2}$

3. Facemasks: Facemasks are made from different diameters of plastic or rubber tubing or welded steel or aluminium and are coated with a vinyl plastisol coating. The earliest facemask design introduced into football in the 1950 s consisted of a single bar that was contoured. It provides the maxilla with different degrees of defence horizontally from an extended finger, a clenched fist, an forearm or a helmet directed towards the zygomatic nasal pyramid or mandibular arch respectively. ${ }^{17}$ One major disadvantage of the facemask is that it has a protruding object within the ready grasp of an opposing player. When an opponent pulls or twists the facemask during a match, serious physical consequences such as damage to the muscle, neck or spinal column will result. ${ }^{18}$

\section{SPORTS RELATED DENTAL IMPLICATIONS}

- Sports drinks, especially carbonated, are often used by professional athletes and amateur sports people for rehydration and replacement of electrolytes during highly aerobic activities. Such liquids have a negative effect on the teeth due to the low $\mathrm{pH}$ and the inclusion of citric acid in its formulation, which, if ingested inappropriately and with high volume, may be highly erosive for tooth tissue. ${ }^{19}$

- As the pools are chlorinated to reduce bacterial contamination and algae, the swimming sports person are affected with biocorrosion enamel. ${ }^{19}$

- Divers can also experience barodontalgia in relation to water sports, which is known to be an intraoral discomfort evoked by increases in barometric pressure. Most common oral diseases reported as possible sources of barodontalgia: unsatisfactory dental restorations (30.31\%), dental caries without pulp involvement (29.2\%), infammation of the pulp / periradicular necrotic $(27.8 \%)$, vital pulp pathology (13.9\%) and recent dental treatment (barodontalgia postoperatively, $11.1 \%$ ). ${ }^{20,21}$ In addition to the need for dental care, the possible effects include aspiration or swallowing of the fragment and pain, which may lead to injury or disturbance while diving. ${ }^{22}$ The dentist should therefore carry out regular examinations and preventive measures for diving patients, including periapical and vitality tests, with special attention to apical pathology, faulty restorations and secondary caries lesions. ${ }^{23}$

\section{MANAGEMENT OF DIFFERENT OROFACIAL INJURIES}

The management of different orofacial injuries is shown in table 3 .

\section{CONCLUSIONS}

It is an ancient saying that "Prevention is better than cure". This holds true for orofacial injuries in sport events. Sport's person will realize that oral security by correctly fitting mouthguards, helmets, and face masks does not hamper their ability to compete. 3 It is the dentist's duty as a health professional to stay informed and transfer the knowledge on to the society on sports dentistry issues.6 Gone are those days when we had to suffer with the unesthetic profiles, however in today's world we have advancement in dentistry and can provide esthetic look to any traumatic injury. People need to update themselves regarding the handling of such patients and the various treatment modalities. After all everybody's smile is precious and it needs to be protected.

\section{REFERENCES}

1. Sachdev R, Garg K, Singh G. Sports Dentistry and Role of a Dentist: A Review. International Journal of Medical and Oral Research 2018;3(2):1-3.

2. RamagoniKN, Singamaneni KV, Rao RS, Karthikeyan J. Sports dentistry: A review. Journal of International Society of Preventive and Community Dentistry 2014;4(3):139-146.

3. Pichika S, Manjunath C, Krishnamurthy A, Shilpashree KB, Madhusudhan S, Vandakudri S. Sports Dentistry-A Review. International Journal of Current Research 2019;11(1):177-183.

4. Hegde V, Kiran DN, Anupama A. Mouthguard in sports: A review. Indian J Stomatol 2012;3:50-2.

5. Buch A, Shah S, Kariya BP, Mulchandani V. Recognizing and Plugging the Gaps toward Holistic 


\section{Abrasion}

An abrasion is a wound to the skin or mucosa caused by superficial damage. Abrasions occur as a result of friction, such as scraping between exposed skin and an object. Abrasions involving and extending up into the subcutaneous layer are known to be avulsions.

\section{Contusions}

A contusion, usually called a bruise, is a tissue hematoma without a surface split. This results from blunt trauma by physical force. Contusions may seem simply a hemorrhage of the soft tissue; nevertheless, evaluation is required for any potential osseous and dentoalveolar injuries.

\section{Lacerations}

Some tears in the soft tissue (skin or mucosa) are known as laceration. Lacerations in the skin are extremely common. Lacerations occur from sharp-edged devices, such as a knife, razor or glass, even they also occur from underlying fractures in the bone. Depending on the injury mechanism, lacerations may appear linear, jagged, or stellate. It ahould be ruled out if there is any damage to deeper structures such as nerves, vessels, ducts, muscles, and glands.

\section{Dentoalveolar Injuries \\ i) Crown fracture:}

Crown fractures, which affect the coronal portion of the teeth, can be limited to the enamel or involve the dentin and/or the pulp.

\section{ii) Root fracture}

It involves the root of teeth. This could be impossible to diagnose clinically without radiological analysis.

\section{iii) Tooth concussion}

When the tooth is sensitive to touch and pressure without mobility or displacement, it is called as tooth concussion.

\section{iv) Tooth subluxation}

When the tooth is loose or mobile in the socket but is not displaced, is called as subluxation.

\section{v) Tooth avulsion}

Tooth avulsion is a complete displacement of the tooth from its alveolar socket; therefore, pulpal function and periodontal function can be substantially affected.
Thoroughly wash with saline. Deeper abrasions can require local anesthetics, and possibly a scrub brush. Topical and systemic antibiotics are also given. Aside from the daily oral hygiene, intraoral mucosal abrasions typically need no care. Maxillofacial surgeon is recommended for deeper abrasions.

The swelling is decreased by ice or pressure dressings. The body may resorb the hematoma over time, and the bruise can change colors through the healing process. If the hematoma is expanding, then surgical intervention may be required.

To remove foreign particles the field should be properly washed with copious saline irrigation. Local anesthetics is required, and possibly a scrub brush. Before closure, there should be proper hemostasis. Adhesive is required for small lacerations rather than sutures. Inside out closure is followed. For example, in a throughand-through laceration of the lip closure should be in the following order: (1) oral mucosa first to seal; (2) muscle tissue; (3) subcutaneous tissue; (4) skin. Open drainage is given in grossly contaminated wounds.

Treatment depends upon the fracture intensity. Simple enamel smoothing and no acute treatment is required in case of enamel fracture. Dentin fracture will likely require restorative treatment and referral to a dentist. Crown fractures extending into the pulp will possibly require root canal therapy, and should be referred to a dentist or endodontist.

Root canal therapy, post and core, and a prosthesis is needed if it is near the crown. However if it is in the middle to apical third of the root, repositioning and immobilization is needed for 2 to 4 months. Removal of tooth is required in apical root fractures.

Enameloplasty on the opposing tooth gives a symptomatic relief. Periodic follow-up by a dentist are recommended.

Similar to tooth concussion, however splinting and immobilization for 7-10 days is required for significantly mobile teeth.

The prognosis for avulsed teeth can vary greatly based on many factors, including out - of-alveolus (extra-alveolar) period, the current periodontal condition, the occurrence of large dental restorations, alveolar socket destruction, gross inflammation, and the method of preservation before reimplantation. There is no need of reimplantation in deciduous teeth. 
Extra-alveolar time: The goal is to get the avulsed tooth reimplanted as soon as possible.

The highest prognosis is for teeth reimplanted within 20 minutes and poor prognosis is when repimplanted after 2 hours.

Preservation and handling: In order to maintain the vitality of periodontal ligament (PDL) cells on the root surface, the tooth should only be handled by the crown and not by the root. The best available medium should be used for gentle rinsing of tooth (not scrubbed or brushed). Hanks balanced salt solution (HBSS) or saline solution is the ideal storage medium. However, these solutions may not be available everywhere, in such scenario milk has been considered as the best accessible medium as it is shown to maintain vitality of the PDL cells. Infact patient's own saliva (keeping the tooth in the vestibule of the mouth) is the next best method, but this technique is not advised if a head injury is involved. Because to its hypotonicity, water is the least preferred media, ias it causes the lysis of PDL cells. When rinsed gently, the patient must try to re-implant the tooth into the socket and keep it in place when en route to the dentist or emergency room.

\section{vi) Alveolar bone fracture:}

Alveolar bone fractures include damage to the alveolar process in the presence or absence of teeth. Other tooth injuries such as tooth displacement, crown fractures, root fractures, and softtissue injuries are also associated with these fractures.

The goal is proper repositioning and stabilization. Wire splint, plastic splint, or arch bar ligation may need immobilization for 46 weeks to promote osseous healing. Copious irrigation and softtissue suturing should be done as needed. ${ }^{24}$

Table 3. Management of Different Orofacial Injuries

Pediatric Dental Care. Journal of Integrated Health Sciences 2019;7(1):3-7.

6. Chopra A, Rao CN, Gupta N, Vashisth S. Sports dentistry: Role of dentist in protecting a winning smile. Saudi Journal of Sports Medicine 2013;13(2):747.

7. Saini R. Sports dentistry. National Journal of Maxillofacial Surgery 2011;2(2):129-31.

8. Selva MS, Aparna S, Madan KD. Prevalence of orofacial injuries in contact sports: A systematic review. International Journal of Physical Education, Sports and Health 2019; 6(3):39-46.

9. Saini R. Sports dentistry. National Journal of Maxillofacial Surgery. 2011; 2(2):129-131.

10. Agali RC, Mathur A, Suvarna M, Verma S, Ghosh S. Insight to Epidemiology of Sports Related Dental Injuries. International Journal of Oral Health and Medical Research 2016;2( 6):141-4.

11. David T, Soporowski N. Epidemiology of Orofacial Sports Related Injuries. Dental Clinics of North America 2000;44(1):1-18.

12. Pinkham JR, Kohn DW. Epidemiology and Prediction of Sports Related Traumatic Injuries; Dental Clinics of North America 1991; 35(4):609-26.

13. Kumamoto PD, Maeda Y. A literature review of sports-related orofacial trauma. General Dentistry 2004;52(3):271-80.

14. Alsaey M. Sports Related Jaw Fractures. Online
PDF. Available from: http:// www.aspetar.com/journal/upload/PDF/20131220102931. $p d f$. [Last Accessed on $15^{\text {th }}$ January, 2020]

15. Guevara PA, Ranalli DN. Techniques for mouthguard fabrication. Dental Clinics of North America 1991;35(4):667-82.

16.Padilla RR, Lee TK. Pressure-laminated athletic mouth guards: A step-by-step process. Journal of the California Dental Association 1999;27(3):200-9.

17. Watterson JS. Inventing modern football. American Heritage 1988;39:113.

18. Reed RV Jr. Origin and early history of the dental mouthpiece. British Dental Journal 1994;176(12):478-8o.

19. Soares VP, Tolentino BA, Machado CA, Dias BR, Coto PN. Sports dentistry: a perspective for the future. Revista Brasileira de Educação Física e Esporte 2014;28(2):351-8.

20. Zadik Y. Barodontalgia. Journal of Endodontics 2009;35(4):481-5.

21. Zadik Y, Chapnick L, Goldstein L. In-flight barodontalgia: analysis of 29 cases in military aircrew. Aviation Space and Environmental Medicine 2007;78:593-6.

22. Peker I, Erten H, Kayaoglu G. Dental restoration dislodgment and fracture during scuba diving: a case of barotrauma. Journal of American Dental Association 2009;140(9):1118-21. 
23. Zadik Y, Drucker S. Diving dentistry: a review of the dental implications of scuba diving. Australian Dental Journal 2011;56(3):265-71.
24. Patel BP, Stanton CD, Eric J. Granquist JE. Common Dental and Orofacial Trauma Evaluation and Management. Medical Clinics of North America 2014;98 (6):1261-79.

Source of support: Nil, Conflict of interest: None declared

Cite this article as:

Mir H, Shivalingesh KK, Gangwar C, Ashraf W. Sports Dentistry: A Narrative Review. Int Healthc Res J. 2020;4(4):81-87. https://doi.org/10.26440/IHRJ/0404.07159

AUTHOR AFFILIATIONS: ${ }^{*}$ Corresponding Author)

1. Post Graduate Student [ORCID ID: https://orcid.org/oooo-0oo2-3233-2654)

2. Professor \& Head (ORCID ID: https://orcid.org/oooo-0002-4636-522X)

3. Associate Professor

Department of Public Health Dentistry, Institute of Dental Sciences, Bareilly, India

4. Post Graduate Student, Department of Oral Medicine and Radiology, Vyas Dental College, Jodhpur

(ORCID ID: https://orcid.org/oooo-0002-4828-815X)

Contact corresponding author at: hennamir21[at]gmail[dot]com 